\title{
A Rapid Microbioassay for Discovery of Antagonistic Bacteria for Phytophthora parasitica var. nicotianae
}

\author{
Hancheng Wang, Wenhong Li, Qingyuan Chen, Yanfei Huang, Kai Li, Haiqian Xia, \\ Maosheng Wang, Liuti Cai, Shenghua Shang, and Junxiong Shi
}

First, third, sixth, seventh, eighth, ninth, and tenth authors: Guizhou Tobacco Science Institute, Guiyang 550081, P.R. China; second author: Guizhou Institute of Plant Protection, Guiyang 550006, P.R. China; and fourth and fifth authors: College of Agriculture, Yangtze University, Jingzhou 434025, P.R. China. First, second, and third authors contributed equally. Accepted for publication 20 October 2011.

\begin{abstract}
Wang, H. C., Li, W. H., Chen, Q. Y., Huang, Y. F., Li, K., Xia, H. Q., Wang, M. S., Cai, L. T., Shang, S. H., and Shi, J. X. 2012. A rapid microbioassay for discovery of antagonistic bacteria for Phytophthora parasitica var. nicotianae. Phytopathology 102:267-271.

A simple, rapid, small-scale microbioassay for infection of tobacco seedlings by Phytophthora parasitica var. nicotianae was developed here. This assay uses tobacco seedlings cultivated in petri dishes for a standardized method for quantitation of initial zoospore inocula and highthroughput screening of antagonistic bacteria. Zoospore inocula between $10^{2}$ to $10^{5}$ spores per petri dish were inoculated on 14-day-old tobacco seedlings for the susceptibility test. The optimum inocula was established to be ten thousand zoospores. One hundred and fifty pure culture bacteria

with different pigments, growth rates, and morphologies were isolated from rhizosphere soil of tobacco and screened for protective ability against tobacco black shank. Fifteen bacteria presented high activity against $P$. parasitica on tobacco seedlings. They were identified by Biolog GEN III MicroPlate and distributed as Bacillus amyloliquefaciens, B. licheniformis, Paenibacillus pabuli, B. atrophaeus, B. subtilis, B. pumilus, and B. endophyticus, respectively. Four antagonists chosen randomly from the 15 bacteria all exhibited the same $100 \%$ protective activity in planta as that in the petri dishes. This microassay proved to be a rapid, reproducible, and efficient method for screening of potential biological agents or microorganisms and may be useful for studying mechanisms of infection and control of Phytophthora spp. under hydroponic conditions.
\end{abstract}

Phytophthora parasitica var. nicotianae (P. parasitica) Breda de Haan causes black shank of tobacco (Nicotiana tabacum L.) in most tobacco-growing regions of the world. It has a host range of more than 72 genera of Solanaceae plants (7), particularly tobacco. The impact of this pathogen on tobacco is enormous $(5,8,15,20)$. Common annual losses attributed to black shank approach $85 \%$ in China (24). Currently, black shank is managed through the use of resistant cultivars, crop rotation, and the fungicide metalaxyl (23). However, it is still a major problem for farmers and there are increasing concerns over environmental problems and metalaxyl-resistant strains of $P$. parasitica (4). The development and application of microbial agents is one of the useful alternative measures and has been used successfully on many crops $(3,6,11,19)$.

Biological control of Phytophthora spp. has been researched for many years worldwide. However, most of the microorganisms are easily influenced by the environment and normally have poor stability. To the best of our knowledge, few microorganisms which are antagonistic in the field are available. Given the enormous economic impact of Phytophthora diseases worldwide, discovery of new and novel biological control agents to manage tobacco black shank is an important priority in disease management. Plenty of fungi, bacteria, and actinomyces have been screened in petri dishes $(9,14,17)$. However, the in vitro results normally are insufficient. Efficacy assessments in vivo are normally conducted on greenhouse-grown plants. This method is

Corresponding author: J. Shi; E-mail address: xiaobaiyang126@ hotmail.com

* The $e$-Xtra logo stands for "electronic extra" and indicates that Figures 1, 2, and 3 appear in color online.

http://dx.doi.org/10.1094/PHYTO-09-11-0247

(c) 2012 The American Phytopathological Society time consuming, material and labor intensive, and requires relatively large quantities of test microorganisms. The in vivo assays often supplement in vitro studies; these are tedious and relatively large scale. A need exists for a rapid, quantitative, efficient, and reproducible microbioassay method to screen microorganisms for potential control of black shank and other Phytophthora diseases.

Therefore, the objectives of the current study were (i) to standardize initial inocula concentrations, (ii) to screen potential antagonistic bacteria for control of infection of tobacco by $P$. parasitica on tobacco seedlings under hydroponic conditions in petri dishes, (iii) to compare the microbioassay with the efficacy assay conducted on greenhouse-grown plants, and (iv) to identify antagonistic bacteria with Biolog GEN III MicroPlate.

\section{MATERIALS AND METHODS}

Fungal strain and culture conditions. One isolate of $P$. parasitica, with wild-type sensitivity and pathogenicity to tobacco, was selected as the modal specie for assay development. The isolate was grown and maintained on lima bean agar medium (60.0 $\mathrm{g}$ of lima beans per liter boiled for $1 \mathrm{~h}$ and $16.0 \mathrm{~g}$ of agar per liter), in a controlled climate cabinet at $25^{\circ} \mathrm{C}$ in darkness. For zoospore production, agar plugs were removed from the edge of an actively growing culture and placed in petri dishes containing $8 \mathrm{ml}$ of $10 \%$ V8 liquid medium (10\% V8, $100 \mathrm{ml}$ of Campbell's V8 juice to $900 \mathrm{ml}$ of sterile water, and $0.2 \mathrm{~g}$ of $\mathrm{CaCO}_{3}$ ). Following a $96 \mathrm{~h}$ incubation period at $25^{\circ} \mathrm{C}$ in light, the suspension was filtered through a double layer of sterile cheesecloth (Grade \#40: $24 \times 20$ threads per inch) to remove mycelia fragments, and the resulting sporangial suspension was maintained at $4{ }^{\circ} \mathrm{C}$ for $30 \mathrm{~min}$ and then at $25^{\circ} \mathrm{C}$ for $2 \mathrm{~h}$ in the dark to release the zoospores (23). For long-term storage, 5-mm agar plugs from the 
leading edge of individual colonies were transferred into several sterile $1.5-\mathrm{ml}$ microcentrifuge tubes containing $1 \mathrm{ml}$ of sterile distilled water, and tubes were stored in the dark at $15^{\circ} \mathrm{C}(1,2)$.

The susceptible tobacco ( $N$. tabacum) cultivar Honghuadajinyuan was used as host of black shank in this study. For the microbioassay, tobacco plants were cultivated $\left(25^{\circ} \mathrm{C}\right)$ in petri dishes containing filter papers moistened with $5 \mathrm{ml}$ of Hoagland's solution and were grown from sterile seeds at 12 plants per petri dish (90 $\mathrm{mm}$ in diameter). When two leaves were fully developed 3 weeks later, the plants were ready.

Standardization of inoculum concentration. Various inoculum concentrations were determined here for use in the screening of antagonistic bacteria. Zoospores of P. parasitica were collected as mentioned above. Inoculum concentrations were quantified by the use of a hemacytometer, and dilutions were made with sterile distilled $\mathrm{H}_{2} \mathrm{O}$ to obtain $1 \times 10^{2}, 1 \times 10^{3}, 1 \times 10^{4}$, and $1 \times 10^{5}$ zoospores/ml, respectively. One $\mathrm{ml}$ of various inocula was added to the tobacco seedlings. After inoculation, the petri dishes were incubated at $25^{\circ} \mathrm{C}, 100$ to $120 \mu \mathrm{Em}^{-2} \mathrm{~S}^{-1}$, relative humidity of $>80 \%$, and $16 \mathrm{~h}$ light per day for disease development. Number of diseased seedlings was checked 7 days after inoculation. The test was repeated twice, with three replications of each treatment.

Soil sampling and isolation of antagonistic bacteria. During the harvesting time of tobacco in 2010, rhizospheric soil about $15 \mathrm{~cm}$ away from healthy tobacco stems was collected from Fuquan and Libo tobacco commercial fields in Guizhou Province, southwest China. Several samples were selected randomly using an open-end soil borer ( $20 \mathrm{~cm}$ in depth, $2.5 \mathrm{~cm}$ in diameter) as described by Lee and Hwang (13). Soil samples were taken from a depth of 10 to $20 \mathrm{~cm}$ below the soil surface. The soil of the top region (10 cm from the surface) was excluded. Samples were airdried at room temperature for 7 to 10 days and then passed through a $0.8-\mathrm{mm}$ mesh sieve and were preserved in polyethylene bags at room temperature before use. Five grams of air-dried soil was mixed with $45 \mathrm{ml}$ of sterile distilled water. The mixtures were shaken vigorously for $1 \mathrm{~h}$ and then allowed to settle for $1 \mathrm{~h}$. Portions $(0.5 \mathrm{ml})$ of soil suspensions (diluted $\left.10^{-1}\right)$ were transferred to $4.5 \mathrm{ml}$ of sterile distilled water and subsequently diluted to $10^{-2}, 10^{-3}, 10^{-4}, 10^{-5}$, and $10^{-6}$. Aliquots of $100 \mu \mathrm{l}$ of $10^{-3}$ to $10^{-6}$ soil dilutions were inoculated onto the surface of NA (beef extract [0.3\%], peptone [0.5\%], and agar [1.5\%] in water [wt/vol]) medium plates (18). After inoculation, the petri dishes were placed at $30^{\circ} \mathrm{C}$ in darkness for $24 \mathrm{~h}$. Bacteria with different pigments, growth rates, and morphologies were isolated from NA plates and refrigerated as pure cultures before use.

Screening of antagonistic bacteria. Pure bacterial solutions were incubated in NB (beef extract [0.3\%] and peptone [0.5\%] in water [wt/vol] ) for $12 \mathrm{~h}$, and $1 \mathrm{ml}$ of each bacterial solution $(1 \times$
$10^{8} \mathrm{CFU} / \mathrm{ml}$ ) was added to the tobacco plants incubated in the petri dishes mentioned above. Afterwards, the petri dishes were incubated in the dark for $12 \mathrm{~h}$. An additional $1 \mathrm{ml}$ of a zoospore suspension adjusted to a concentration of $1 \times 10^{4}$ spores $/ \mathrm{ml}$ was added to each petri dish for inoculated treatments. The control was treated with just $1 \mathrm{ml}$ of zoospore suspension. After inoculation, the petri dishes were incubated under the same conditions mentioned above. All incubation conditions were maintained similarly throughout the experiments. Results were obtained 7 days after inoculation based on a 0 to 5 scale: 0 , no visible disease symptoms; 1 , leaves slightly wilted with brownish lesions beginning to appear on stems; 2, 30 to $50 \%$ of entire plant diseased; 3,50 to $70 \%$ of entire plant diseased; 4,70 to $90 \%$ of entire plant diseased; and 5, plant dead (21). The test was repeated twice, with three replications of each treatment.

Greenhouse bioassay in planta. For efficacy assay, four bacteria ( $\mathrm{Hl} 1, \mathrm{Hl}$, H19, and $\mathrm{Hl13}$ ) with $100 \%$ protection were chosen randomly from the above microbioassay and were utilized here. Tobacco plants were cultivated in the greenhouse $\left(20\right.$ to $\left.30^{\circ} \mathrm{C}\right)$ and grown from seedlings at one plant per 0.2-liter pot with sandy loam soil. They were inoculated when six leaves were fully developed 4 weeks later. Thirty milliliters of pure bacterial solutions at a concentration of $1 \times 10^{8} \mathrm{CFU} / \mathrm{ml}$ was added to the pot, and $24 \mathrm{~h}$ later, an additional $30 \mathrm{ml}$ of a zoospore suspension $\left(4 \times 10^{4}\right.$ spores $/ \mathrm{ml}$ ) was added to the pot for inoculated treatments. Twelve plants were treated per treatment, and the experiment was conducted twice. Results were obtained 30 days after inoculation according to the same method mentioned above.

Identification of antagonistic bacteria. All antagonistic bacteria were grown on Biolog BUG agar for identification by the

TABLE 1. Effect of different inoculum concentrations on the susceptibility of cultivar Hongda tobacco seedlings to infection by Phytophthora parasitica

\begin{tabular}{lccccc}
\hline \multirow{2}{*}{$\begin{array}{l}\text { Inocula } \\
\text { (spores/ml) }\end{array}$} & \multicolumn{2}{c}{ Infection ratio $(\%)$} & & \multicolumn{2}{c}{ Disease incidence } \\
\cline { 2 - 3 } \cline { 5 - 6 } \cline { 5 - 6 } & $\mathrm{Mean}^{\mathrm{y}}$ & $\mathrm{SE}^{\mathrm{z}}$ & & $\mathrm{Mean}^{\mathrm{y}}$ & $\mathrm{SE}^{\mathrm{z}}$ \\
\hline 0 & $0 \mathrm{c}$ & 0 & & $0 \mathrm{~d}$ & 0 \\
$1 \times 10^{2}$ & $70.83 \mathrm{~b}$ & 1.78 & & $59.17 \mathrm{c}$ & 1.39 \\
$1 \times 10^{3}$ & $87.50 \mathrm{~b}$ & 1.31 & & $77.50 \mathrm{~b}$ & 1.11 \\
$1 \times 10^{4}$ & $100 \mathrm{a}$ & 0 & & $100 \mathrm{a}$ & 0 \\
$1 \times 10^{5}$ & $100 \mathrm{a}$ & 0 & & $100 \mathrm{a}$ & 0 \\
\hline
\end{tabular}

x Zoospore inocula of $P$. parasitica added to tobacco seedlings incubated on petri dishes.

y Mean value from two independent assays, with 12 replicate tobacco seedlings per treatment in each assay. Means not followed by a common letter are significantly different $(P \leq 0.05)$ according to least significant difference for each inoculum.

${ }^{\mathrm{z}}$ Standard error of the mean for two independent assays.

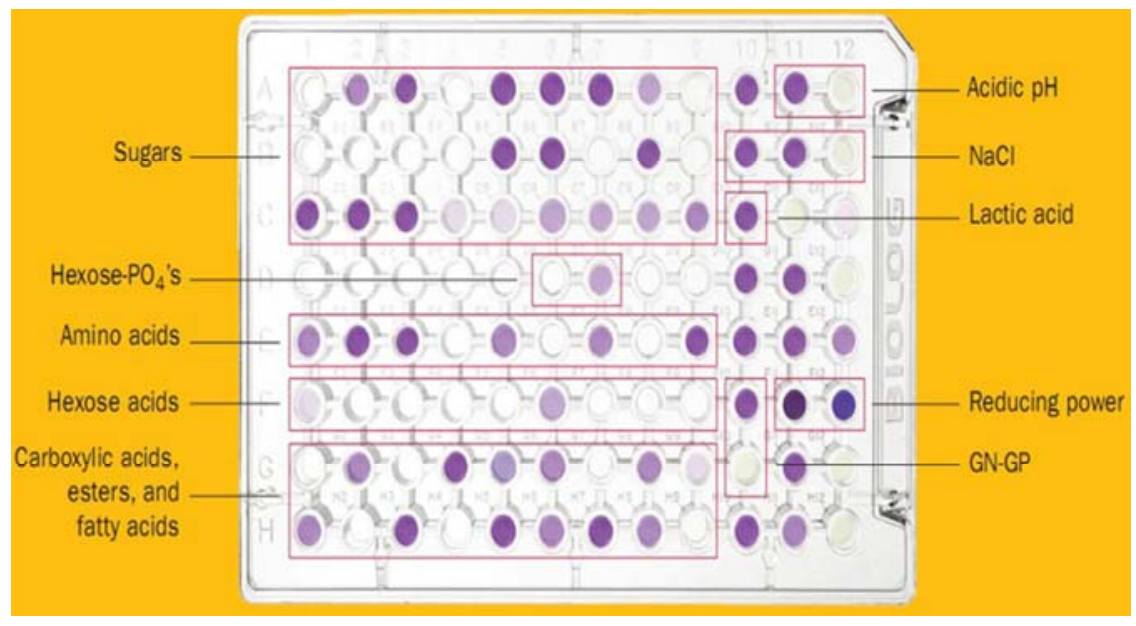

Fig. 1. Biolog GEN III MicroPlate composed of 71 carbon sources plus 23 chemical sensitivity assays. 
Biolog system (Biolog Inc., Hayward, CA). In preparation for analysis, colonies were picked from pure cultures of bacteria and were plated as a lawn of bacteria onto a BUG agar plate. Separate plates were set up for each strain to be analyzed. The Biolog Microlog Bacterial Identification System consists of databases combined with specialized 96-well plates (test panels). A panel of 71 carbon source utilization assays and 23 chemical sensitivity assays (Fig. 1) provides a "Phenotypic Fingerprint" of the microorganism that can be used to identify it at the species level (10). GEN III MicroPlate test panels were used for identification according to the manufacturer's instructions throughout the experiment.

Data analysis. Results of laboratory and growth chamber experiments were reported. Data from repeated experiments were combined for analysis since variances between experiments were homogeneous. Inhibition on disease development was calculated as $\%$ protection $=100 \times(1-x / y)$, where $x$ and $y$ were disease incidence in treated-challenged and control (untreated-challenged) tobacco seedlings, respectively (22).

\section{RESULTS}

Inoculum concentration effects. Inoculum of various zoospore concentrations had a significant effect on tobacco seedling infection by $P$. parasitica. Disease incidences and infection ratios increased greatly with the enhancement of inocula of the pathogen. Inoculum concentrations of $1 \times 10^{4}$ and $1 \times 10^{5}$ zoospore $/ \mathrm{ml}$ both provided a mean disease incidence of 100 over the course of the two repeated experiments. In contrast, inoculations of $1 \times 10^{2}$ and $1 \times 10^{3}$ zoospore $/ \mathrm{ml}$ produced mean disease incidences of 59.17 and 77.50 and infection ratios of 70.83 and $87.50 \%$, respectively (Table 1 ).

Isolating and screening of antagonistic bacteria. In isolating and screening for bacteria having antagonistic activity against $P$. parasitica, the causal agent of tobacco black shank, 150 isolates of soil bacteria from tobacco rhizosphere were isolated. When adding test bacteria solution $12 \mathrm{~h}$ before that of the pathogen, 15 of the tested bacteria exhibited $100 \%$ protective efficacy, with a disease incidence value of 0 (Table 2). The others had much less activity, with highest disease incidence value of 100 (data not shown). Additionally, during the 7-day-incubation period, all control treatments resulted in the same disease incidence value of 100, and all tobacco seedlings died (Fig. 2).

Greenhouse bioassay in planta. The in planta efficacy of selected antagonists for the control of $P$. parasitica in tobacco plants was evaluated under greenhouse conditions and there were significant differences 30 days after transplanting. At 45 days after transplanting, antagonist bacteria significantly reduced tobacco black shank incidence compared with that of the control (Fig. 3). Generally, a positive correlation (data not shown) was found between petri dish screening and in planta suppression of disease.

Identification of antagonistic bacteria. All 15 selected antagonistic bacteria were identified to species level by Biolog GEN III

TABLE 2. Identification of antagonistic bacteria against tobacco black shank with Biolog GEN III MicroPlate ${ }^{\mathrm{x}}$

\begin{tabular}{|c|c|c|c|c|c|}
\hline Strain number & Disease incidence ${ }^{y}$ & Species & Similarity & Distance & Organism type \\
\hline Hl1 & 0 & Bacillus amyloliquefaciens & 0.653 & 5.055 & $\mathrm{GP}^{\mathrm{z}}$ \\
\hline $\mathrm{H} 12$ & 0 & Bacillus amyloliquefaciens & 0.660 & 4.854 & GP \\
\hline $\mathrm{H} 13$ & 0 & Bacillus amyloliquefaciens & 0.638 & 5.252 & GP \\
\hline $\mathrm{Hl} 4$ & 0 & Bacillus amyloliquefaciens & 0.582 & 6.166 & GP \\
\hline $\mathrm{H} 15$ & 0 & Bacillus amyloliquefaciens & 0.555 & 5.611 & GP \\
\hline Hl6 & 0 & Bacillus amyloliquefaciens & 0.555 & 5.470 & GP \\
\hline $\mathrm{H} 17$ & 0 & Bacillus licheniformis & 0.533 & 4.751 & GP \\
\hline $\mathrm{H} 18$ & 0 & Bacillus licheniformis & 0.501 & 5.164 & GP \\
\hline $\mathrm{H} 19$ & 0 & Paenibacillus pabuli & 0.569 & 6.340 & GP \\
\hline H110 & 0 & Paenibacillus pabuli & 0.603 & 5.798 & GP \\
\hline H111 & 0 & Bacillus atrophaeus & 0.610 & 5.694 & GP \\
\hline Hl12 & 0 & Bacillus atrophaeus & 0.607 & 4.246 & GP \\
\hline $\mathrm{H} 113$ & 0 & Bacillus subtilis & 0.596 & 5.861 & GP \\
\hline $\mathrm{H} 114$ & 0 & Bacillus pumilus & 0.596 & 5.273 & GP \\
\hline H115 & 0 & Bacillus endophyticus & 0.535 & 6.838 & GP \\
\hline
\end{tabular}

${ }^{x}$ Identification values of antagonistic bacteria with Biolog GEN III MicroPlate after 16 to 24 h incubation.

y Values obtained from antagonistic bacteria screening bioassay on petri dishes.

z Gram-positive bacteria.

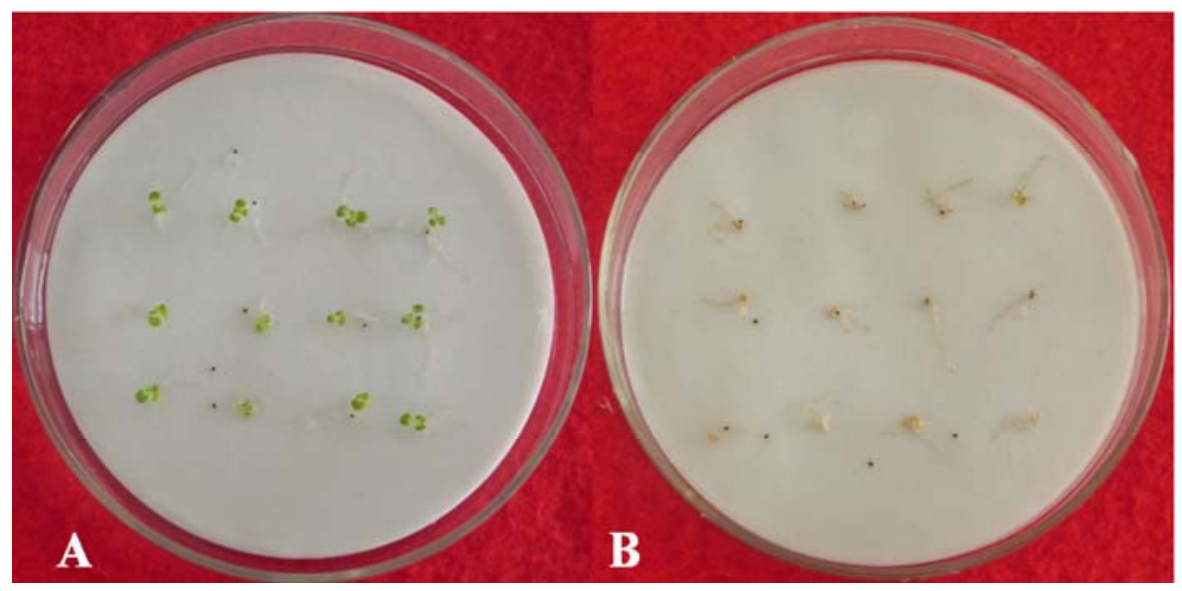

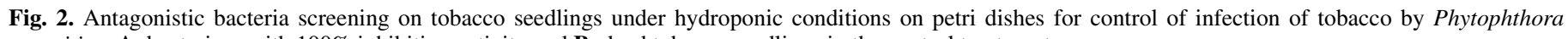
parasitica: $\mathbf{A}$, bacterium with $100 \%$ inhibition activity and $\mathbf{B}$, dead tobacco seedlings in the control treatment. 


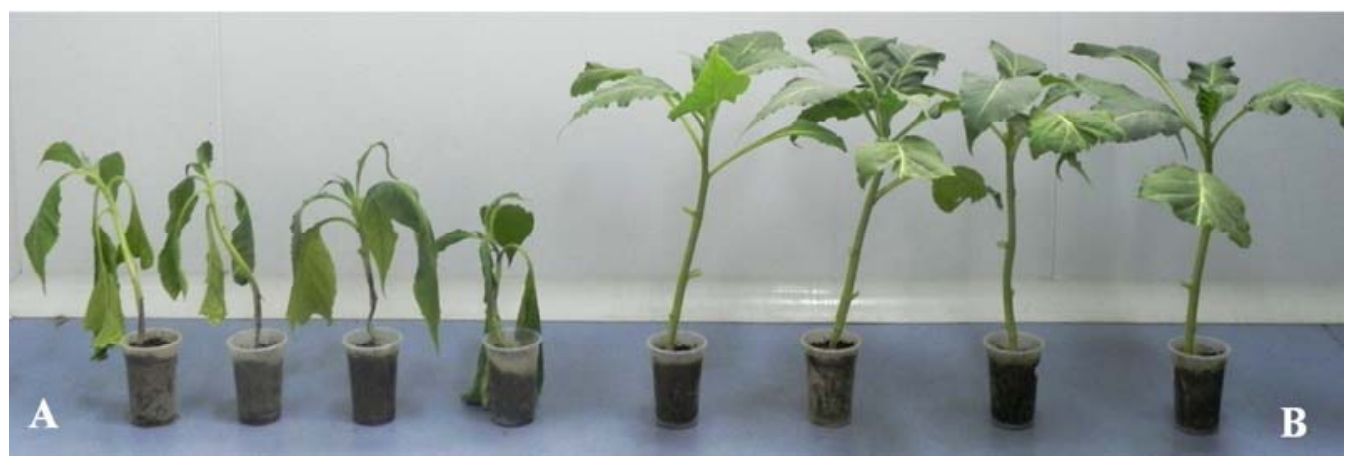

Fig. 3. In planta efficacy of a select antagonist for the control of Phytophthora parasitica in tobacco plants under greenhouse conditions 45 days after transplanting: A, control and $\mathbf{B}$, antagonistic bacterium treatment.

MicroPlate. If the similarity value was $>0.5$ during a 16 to $24 \mathrm{~h}$ incubation period, the identification result was acceptable. They were all gram-positive bacteria with similarity value of $>0.5$. The isolates identified included seven genera: five Bacillus amyloliquefaciens species, two B. licheniformis species, two Paenibacillus pabuli species, two $B$. atrophaeus species, one $B$. subtilis species, one B. pumilus species, and one B. endophyticus species (Table 2).

\section{DISCUSSION}

In this investigation, we have developed a standardized microscale bioassay for screening potential antagonistic bacteria against $P$. parasitica. Whereas any one bioassay in vitro will likely be consistent with the in planta assay, the microbioassay provides a rapid, reproducible, simple technique for testing quantities of sample. It may provide a preliminary screen for agents that will be useful in the field for control of tobacco black shank, although not all bacteria that control infection on tobacco seedlings can be expected to work in soil and in the field as well.

Zoospores of $P$. parasitica were the primary infective propagule, and homogenized zoospore suspensions were considered to be a more appropriate assay target than mycelium (12). The optimum concentration of zoospores was quite important for standardization of inoculum concentration throughout the bioassay. Both $10^{4}$ and $10^{5}$ zoospores could generate the same disease incidence in tobacco seedlings during a short incubation period, while $10^{4}$ zoospore treatment was chosen as the inoculum concentration for use in the assays because it combined technical expediency with consistency of results and it was easier to prepare the mounts of zoospores compared with that of $1 \times 10^{5}$ zoospores.

In this study, antagonistic bacteria were identified by Biolog GEN III MicroPlate. To the best of our knowledge, this is the first use of GEN III MicroPlate, the new microplate product of Biolog Corporation, in identification of antagonistic microorganisms. The test panel provides a standardized micromethod using 94 biochemical tests to profile and identify a broad range of gramnegative and gram-positive bacteria. Biolog's advanced system of phenotypic testing is a natural progression from the traditional approaches to mycological identification. However, identification with the Biolog system is not enough for allocating an identity to the isolated strains. In contrast, bacterial identification based on polymerase chain reaction assays is always restricted by the sequencing information, database, and primers used. Phenotypic identification is quite interesting for precise genetic identification, however phenotype testing and genotype testing can complement one another (16).

In conclusion, the four bacteria have proven to be consistently efficient in the control of $P$. parasitica disease in an in planta biocontrol assay under greenhouse conditions. Field studies should be undertaken in the next step to confirm the effectiveness of the antagonistic strains under natural conditions and their modes of action. In addition, this microbioassay provides an opportunity to screen useful microorganisms against other Phytophthora spp.

\section{ACKNOWLEDGMENTS}

This work was supported by Guizhou Science Technology Foundation ([2011]2337), Guizhou Tobacco Company (200804, 200915, 201018), China Tobacco Company (11020100219), and Special Fund for AgroScientific Research in the Public Interest (201103004).

\section{LITERATURE CITED}

1. Ann, P. J., and Ko, W. H. 1990. Growth rate and colony morphology of progenies of zoospores and selfed oospores of Phytophthora parasitica. Mycologia 82:693-697.

2. Boesewinkel, H. J. 1976. Storage of fungal cultures in water. Trans. Br. Mycol. Soc. 66:183-185.

3. Boff, P., Köhl, J., Jansen, M., Horsten, P. J. F. M., Lombaers-van der Plas, C., and Gerlagh, M. 2002. Biological control of gray mold with Ulocladium atrum in annual strawberry crops. Plant Dis. 86:220-224.

4. Cartwright, D. K., and Spurr, J. R. H. W. 1998. Biological control of Phytophthora parasitica var. nicotianae on tobacco seedlings with nonpathogenic binucleate Rhizoctonia fungi. Soil Biol. Biochem. 30:18791884.

5. Dukes, P. D., and Apple, J. L. 1961. Chemotaxis of zoospores of Phytophthora parasitica var. nicotianae by plant roots and certain chemical solutions. Phytopathology 51:195-197.

6. Han, J. G., Sun, L., Dong, X. Z., Cai, Z. Q., San, X. L., Yang, H. L., Wang, Y. S., and Song, W. 2005. Characterization of a novel plant growthpromoting bacteria strain Delftia tsuruhatensis HR4 both as diazotroph and a potential biocontrol agent against various plant pathogens. Syst. Appl. Microbiol. 28:66-76.

7. Hickmann, C. J. 1958. Phytophthora plant destroyer. Trans. Br. Mycol. Soc. 41:1-13.

8. Jacobi, W. R., Main, C. E., and Powell, N. T. 1983. Influence of temperature and rainfall on the development of tobacco black shank. Phytopathology 73:139-143.

9. Jin, F. L., Ding, Y. Q., Ding, W., Reddy, M. S., Dilantha Fernando, W. G., and Du, B. H. 2011. Genetic diversity and phylogeny of antagonistic bacteria against Phytophthora nicotianae isolated from tobacco rhizosphere. Int. J. Mol. Sci. 12:3055-3071.

10. June, C. M., Roach, K., Levett, P. N., and Lavoie, M. C. 2006. Identification of Streptococcus iniae by commercial bacterial identification systems. J. Microbiol. Methods 67:20-26.

11. Kloepper, J. W., Ryu, C. M., and Zhang, S. 2004. Induced systemic resistance and promotion of plant growth by Bacillus spp. Phytopathology 94:1259-1266

12. Kuhajek, J. M., Jeffers, S. N., Slattery, M., and Wedge, D. E. 2003. A rapid microbioassay for discovery of novel fungicides for Phytophthora spp. Phytopathology 93:46-53.

13. Lee, J. Y., and Hwang, B. K. 2002. Diversity of antifungal actinomycetes in various vegetative soils of Korea. Can. J. Microbiol. 48:407-417.

14. Lemessa, F., and Zeller, W. 2007. Screening rhizobacteria for biological control of Ralstonia solanacearum in Ethiopia. Biol. Control. 42:336-344.

15. McCarter, S. M. 1967. Effect of soil moisture and soil temperature on black shank disease development in tobacco. Phytopathology 57:691-695.

16. Morgan, M. C., Boyette, M., Goforth, C., Sperry, K. V., and Greene, S. R. 2009. Comparison of the Biolog OmniLog Identification System and 16S ribosomal RNA gene sequencing for accuracy in identification of atypical 
bacteria of clinical origin. J. Microbiol. Methods 79:336-343.

17. Nguyen, M. T., and Ranamukhaarachchi, S. L. 2010. Soil-borne antagonists for biological control of bacterial wilt disease caused by Ralstonia solanacearum in tomato and pepper. J. Plant Pathol. 92:395-406.

18. Shahidi, B. G. H., Barkhordar, B., Pakgohar, N., Aghighi, S., Biglary, S., Farrokhi, P. R., Aminaii, M., Mahdavi, M. J., and Aghelizadeh, A. 2006. Biological control of Phytophthora drechsleri tucker, the causal agent of pistachio gummosis, under greenhouse conditions by use of actinomycetes. Plant Pathol. J. 5:20-23.

19. Someya, N., Kataoka, N., Komagata, T., Hirayae, K., Hibi, T., and Akutsu, K. 2000. Biological control of cyclamen soilborne diseases by Serratia marcescens strain B2. Plant Dis. 84:334-340.

20. Stokes, G. W., and Litton, G. C. 1966. Source of back shank resistance in tobacco and host reaction to races 0 and 1 Phytophthora parasitica var. nicotianae. Phytopathology 56:678-680.
21. Sun, H. Y., Wang, H. C., Stammler, G., Ma, J. X., and Zhou, M. G. 2010. Baseline sensitivity of populations of Phytophthora capsici from China to three carboxylic acid amide (CAA) fungicides and sequence analysis of cholinephosphotranferases from a CAA-sensitive isolate and CAAresistant laboratory mutants. J. Phytopathol. 158:244-252.

22. Sunwoo, J. Y., Lee, Y. K., and Hwang, B. K. 1996. Induced resistance against Phytophthora capsici in pepper plants in response to DL- $\beta$-aminon-butyric acid. Eur. J. Plant Pathol. 102:663-670.

23. Yuan, S. K., Liu, X. L., Gu, B. G., Dong, J., Jiang, H., and Si, N. G. 2006. Sensitivity of Phytophthora infestans to flumorph: In vitro determination of baseline sensitivity and the risk of resistance. Plant Pathol. 55:258-263.

24. Zhang, X. G., Sun, W. X., and Chang, C. J. 2003. Genetic and pathogenic variation among tobacco black shank strains of Phytophthora parasitica var. nicotianae from the main tobacco growing in China. J. Phytopathol. $151: 259-266$. 